\title{
TO STRUCTURE OR NOT TO STRUCTURE: THE EFFICACY OF AN INTERACTIVE EXERCISE FOR UNDERSTANDING THE IMPORTANCE OF STRUCTURE
}

\author{
SALLY QUINN, LISA-MARIE HENDERSON, ALEX BENJAMIN, KATIE \\ SLOCOMBE
}

\begin{abstract}
:
Essay writing is often a fundamental component of assessment in higher education, therefore we need to find effective ways of encouraging students to develop strong writing skills. This study aimed to evaluate the efficacy of an interactive exercise designed to demonstrate the importance of essay structure and organisation.

During an essay-writing seminar over four academic years, 3rd year undergraduate students $(\mathrm{N}=510)$ were given 5 minutes to assign a grade category (1st, 2:1, 2:2, 3rd) to an essay. Half the students marked a well-structured essay, and half marked a poorly-structured version that contained slightly more content, but students were blind to this manipulation. The grades awarded by the students to each type of essay were then disseminated. We hypothesised that students would award higher marks to the well-structured essay, and that this exercise would increase awareness of the importance of structuring essays. Results revealed that the well-structured essays were significantly associated with high marks (1st/2:1s) and poorly-structured essays significantly associated with low marks (2:2/3rd) and this pattern was consistent across four cohorts. Significantly more students reported that structure was the most important element in essay writing after this exercise than before, indicating it was effective in highlighting the importance of structure, and $91 \%$ of students reported that the session had increased their awareness of the importance of structure.

The results support the use of this exercise to increase student awareness of the importance of essay structure and indicates that actively involving students in the assessment process may improve students' understanding of expectations We hope the exercise assessed in the current study will be used in other educational programmes where essay writing is a core part of assessment.
\end{abstract}

\section{Keywords:}

Essay structure, academic writing, active learning, self-regulation, peer assessment

JEL Classification: 123, Y90

\section{Authors:}

SALLY QUINN, University of York, United Kingdom, Email: sally.quinn@york.ac.uk LISA-MARIE HENDERSON, University of York, United Kingdom, Email:

lisa-marie.henderson@york.ac.uk ALEX BENJAMIN, University of York, United Kingdom, Email: avb508@york.ac.uk KATIE SLOCOMBE, University of York, United Kingdom, Email: katie.slocombe@york.ac.uk 


\section{Citation:}

SALLY QUINN, LISA-MARIE HENDERSON, ALEX BENJAMIN, KATIE SLOCOMBE (2017). To structure or not to structure: the efficacy of an interactive exercise for understanding the importance of structure. International Journal of Teaching and Education, Vol. V(2), pp. 74-92.,

10.20472/TE.2017.5.2.005 


\section{Introduction}

Good written communication skills are essential, both within the university context and more broadly in the wider world. However, claims about declining standards of student writing have been made (Bjork et al., 2006; Lea \& Street, 1998), to the extent that the Economic and Social Research Council (ESRC) funding has been allocated to understanding this issue in a bid to improve performance (e.g. ESRC, 2014). Some argue that an ever-increasing range of writing demands are being made of students (Ganobcsik-Williams, 2010), whilst other research indicates that traditional essay writing continues to dominate across many disciplines and lies at the centre of teaching and learning in higher education (Dearing Report, 1997). For instance, essay writing is often a fundamental component of assessment and is seen as not only an opportunity for students to show their knowledge on a certain topic but as a learning activity (Hounsell, 1997). The process of essay writing can help students gain disciplinary knowledge and develop skills in critical analysis (Hilgers, Hussey \& Stitt-Bergh, 1999), with the expectation that they produce texts that increasingly approximate the conventions of their discipline. Thus, given the emphasis on writing in higher education, an important research question is how best to encourage students to build on their writing skills throughout their time at university and to prevent weaknesses in writing from masking content-based and creative learning. The present study aims to evaluate the efficacy of an interactive exercise aimed at aiding understanding of the importance of structure in an essay.

Coffin et al, (2005) point out that despite essay writing being at the centre of the curriculum in some subjects in higher education, it is often an invisible element. Moreover, they state that there is often an assumption that the rules regarding what constitutes acceptable academic writing is part of the 'common sense' knowledge students have and thus may not be explicitly taught. Another assumption is that if students do indeed lack familiarity with these 'rules', then they will 'pick it up' along the way and through receiving feedback on assignments. Coffin et al propose that there are a number of reasons why this approach is becoming increasingly problematic, including the growth of student numbers (and concomitant difficulties in supporting and nurturing struggling students) and increasingly diverse student populations. In particular, mature students may have more variable recent experience with essay writing and essay writing can be a daunting task for second language students. Daud, Daud \& Kassim (2016) found that poor writing skills in second language students were related to writing anxiety, and Chur-Hansen (2000) found that second language learners were more likely to be more critical of their own writing performance compared to native language users. These populations may be in particular need of support for essay writing, however, changes to the curriculum such as modularisation (i.e., short topic-specific courses, as opposed to academic progression over a year), make the implementation of essay writing courses in the curriculum more difficult.

When marking essays, lecturers focus on both the content and form of the writing, including the text structure and the construction of argument. Lea and Street (1998) 
interviewed academic staff on their views on the elements which contribute to a good piece of writing, reporting that the most prominent and consistent elements included 'structure', 'argument' and 'clarity'. The importance of structure specifically is evident when examining essays of varying quality; structure being a key element which often distinguishes stronger essays from weaker essays. In their analysis of undergraduate essays, Prosser and Webb (1994) examined the degree of 'predictive scaffolding' in essays of varying standard. Predictive scaffolding refers to techniques which make an essay's organisation and structure explicit to the reader (e.g. key themes being outlined in the introduction). They found that the essays that received higher marks incorporated a greater degree of predictive scaffolding than those awarded lower marks. For example, in the weaker essays, the introduction failed to include signposting, and paragraphs were often discrete pieces of information with no or little evidence of logical flow between them. Furthermore, the idea that structure is an important element of a good essay is usually indicated in essay marking guidelines (Andrews, 2010). For example, at the Department of Psychology, University of York, the marking guidelines for essays include phrases such as 'well-organised' and 'logical flow' to describe good quality essays. Both of these phrases are implicit references to good structure. It is clear that structure is a key characteristic of essay writing valued by academic staff and one which is reflected in the marks awarded to essays.

Despite the importance of essay structure from the assessors' perspective, it is not clear that students share this understanding (Lillis \& Turner, 2001) and it is often highlighted as a common weakness in student essay writing (Archer, 2008; Andrews, 2010). Students often report that they know the basic format of essay structure (Crème \& Lea, 2008) - the introduction sets the scene, the main body outlines and develops the argument, and the conclusion brings everything together. However, students are not always aware of how important structure and organisation of an essay are to the quality of the essay. In fact, it is not uncommon for there to be a disparity between students' and staff's expectations of what it means to write a 'good essay' and this can be reflected in divergent student self-assessment and marker assessment of essays (Chur-Hansen (2000). Students' relatively low level of awareness of their own weaknesses relating to essay structure was illustrated by Archer (2008). In an evaluation of the efficacy of a Writing Centre in the University of Cape Town, Archer found a disparity between the focus of student concerns and the main weaknesses that actually needed addressing. Many of the students were approaching the Writing Centre requesting help with the understanding of the topic of the essay and to ask for help in analysing what the essay required. However, in many instances, the key element which required more work was the structure and organisation of the essay. Once this was highlighted to students and they received the necessary support, students reported that it was much easier to tackle future essays. Archer concludes that addressing the requirements of structure and organisation of an essay were the most common issues addressed by the Writing Centre and that by addressing these issues provides "the most immediate and rewarding results" for students (p. 13). Hence, this disparity between student and staff expectations is evident when staff neglect to highlight the importance of the structure 
and expression of ideas within an essay (Andrews, 2010); students need to learn the importance of signposting the reader through the structure of the text (Coffin et al, 2005). The need for this student awareness can be particularly concerning given that, in the UK, support for academic writing is usually aimed at non-native English speakers and mature students (Green, 2016) and even this is usually only provided by Writing Centres where it is the student's responsibility to seek out support (Archer, 2008) and there are numerous barriers to students seeking support (Bennett \& Stevens, 2015). This often leaves the majority of students without any guidance or support with academic writing and subsequently unaware of the relative importance of structuring and organising an essay.

In order to make students more aware of the importance of essay structure, it is important to actively engage them in the process as this can be an effective way of learning (Nicol, 2010). One form of active engagement in essay writing skills is allowing students to mark essays themselves. This allows them to identify weaknesses in content and structure and to reflect on how it could be improved. The hope being, students will proceed to translate this knowledge to their own essay writing. Indeed, previous research suggests that self/peer assessment, when used in combination with conventional teaching methods, encourages students to become more responsible and reflective (Mowl \& Pain, 1995; Dochy, Segers \& Sluijsmans, 1999). This idea also fits with the self-regulation model of assessment and feedback (Nicol \& McFarlane-Dick, 2006). This model suggests that students experience 'internal outcomes' (e.g. changes in perception and motivation) that then have an effect on 'external outcomes' (e.g. essay writing). Involving students in peer/self-assessment processes and encouraging selfreflection can therefore aid students' understanding of the elements that make a good essay (internal outcome) with a view to then improving their own essay writing (external outcome). In addition to this self-regulation approach, it has also been shown that involving students in assessment helps them better understand the expectations of the program of study (Nicol, 2010)

\section{Aims and hypotheses}

This study aimed to evaluate the effectiveness of an interactive exercise in increasing students' awareness of the importance of structuring essays. This exercise was embedded in an essay writing seminar and involved half of the students marking a wellstructured essay, and the other half marking a poorly structured version of the essay. We predicted that despite being blind to the manipulation, students would awards higher marks to the well-structured essay than the poorly structured essay. By showing the students these results during the seminar, we hoped to increase their awareness of the importance of planning and structuring their essays. In this regard, and to measure changes in internal outcomes (Nicol \& McFarlane-Dick, 2006), we asked students from the final two cohorts to rate the importance of structuring before and after this activity and reflect on the efficacy of the exercise. Prior to this exercise, traditional lecture slides 
outlined the expectations of overall essay and paragraph structure. After the exercise, students were also encouraged to take a copy of the essay they had not marked so they could make direct comparisons between the well-structured and poorly-structured essay, allowing them direct access to concrete examples of how to structure an essay well.

\section{Method}

\subsection{Participants}

The participants were final year undergraduate students studying for a BSc in Psychology. Psychology students from this University are predominantly female (approximately 70\%), consistent with national averages. Data from sessions in four academic years were analysed ( $N=510$ comprising $2011 n 112 ; 2013 n$ 97; $2015 n$ 148; $2016 n$ 153). Data from 2012 and 2014 were unavailable due to technical errors.

\subsection{Stimuli and Apparatus}

The essays were hand written by one of the authors (KS) in a style mimicking those of undergraduate essays written under timed examination conditions (see appendix). The essay question was "To what extent can human phobias be explained by classical conditioning?". The well-structured essay began with a plan where the essential arguments were listed. The essay itself had a carefully structured introduction which outlined the aims and structure of the essay, a main body containing point-led paragraphs which flowed logically with explicit links back to the essay question and a final concise concluding paragraph with a clear answer to the essay question. In contrast, the poorly-structured essay contained no plan, the introductory paragraph did not outline the structure of the essay, the fact-driven paragraphs of the main body were poorly organised with few attempts to relate information back to the question, and there was no clear concluding paragraph. Despite the differences in structure, the poorlystructured essay contained more relevant content in the form of an extra paragraph and citation. The well-structured essay was slightly longer than the poorly-structured essay (750 words and 658 words, respectively) due to scaffolding techniques being used and the presence of an introduction and conclusion.

Students were given extracts from the department's marking guidelines to provide a brief description of each overall grade category:

First: Excellent answer, well written, logical, well organised and critical

Upper Second: Comprehensive, well organised, accurate

Lower Second: Adequate, mostly accurate, limited in organisation and scope with no real development of argument

Third: Incomplete answer, sparse information, poorly organised

Their responses were gathered through the use of polling software which allows students to register their responses anonymously through a hand-held 'clicker.' 


\subsection{Design}

A between-subjects design was adopted for the student assessment activity. That is, students graded either the well-structured or poorly-structured essay, and were blind to the manipulation when they marked the essay:

\subsection{Procedure}

In all years (2009-2016), the session was run at the start of the Autumn term for final year Psychology students, and it lasted one hour in a large lecture theatre. The session was focussed on providing students with tips on how to write effective essays under timed examination conditions. All students were provided with clickers at the start of the lecture. They first listened to a short presentation (approximately 25 minutes) on how to write a good essay. This included information on structuring, timing, practicing, and critical analysis. Students from the 2015 and 2016 cohorts were then asked "In your opinion, how important is the structure of an essay in determining your grade?". Students selected from the following answers: 'More important than content,' 'As important as content,' or 'Less important than content.' Following this, students were asked to partake in the essay marking activity. Students in one half of the lecture theatre were given the well-structured essay; the other half were given the poorly-structured essay. The lecture theatre has a central aisle which meant students in the wellstructured essay group could not see the poorly-structured essay and vice versa. This also resulted in students being blind to the manipulation. They were told that "This essay was taken from a previous exam in which students were asked to answer two questions in 90 minutes (i.e., 45 minutes per essay)". They were given 5 minutes to read the essay and then use the clickers to decide whether it should be allocated a $1^{\text {st }}, 2: 1,2: 2$ or a $3^{\text {rd }}$. They were then informed of the structure manipulation and shown the marks they awarded to each type of essay in the form of frequency bar graphs, as a way to demonstrate that the students themselves were sensitive to the importance of structure and that they had relied on structure in making their quality judgements. The 2015 and 2016 cohorts were then asked again to rate the importance of structure in an essay relative to content and finally to respond to the question "To what extent has today's session increased your awareness of the importance of structuring an essay carefully?". Possible responses were 'Not at all,' 'A little' and 'A lot.' At the end of each session, students were given the opportunity to collect a copy of the essay they had not marked so they could make direct comparisons between the two essays.

\section{Results}

The number of students who awarded each degree classification for the essays for each cohort were recorded by the polling software and are shown in figure 1. To test whether there was a significant association between the type of essay marked (well structured/ poorly structured) and the mark awarded (high: $1^{\text {st }} \& 2: 1$; low: $2: 2 ; 3^{\text {rd }}$ ), chi square tests of independence were conducted. When data across all four years were combined 
structured essays were significantly associated with high marks $\left(\chi^{2}(1)=245.92, p\right.$ $<.001)$. The same pattern was consistently observed in each of the cohorts $\left(2011\left(\chi^{2}\right.\right.$ $(1)=61.12, p<.001)$, in 2013, $\left(\chi^{2}(1)=32.11, p<.001\right)$, in $2015\left(\chi^{2}(1)=60.55, p<.001\right)$, and in $2016\left(\chi^{2}(1)=94.98, p<.001\right.$; Figure 1$)$.

Figure 1: Percentage of students awarding each degree classification to the essay they marked for each cohort: (a): 2011; (b) 2013; (c) 2015; (d) 2016
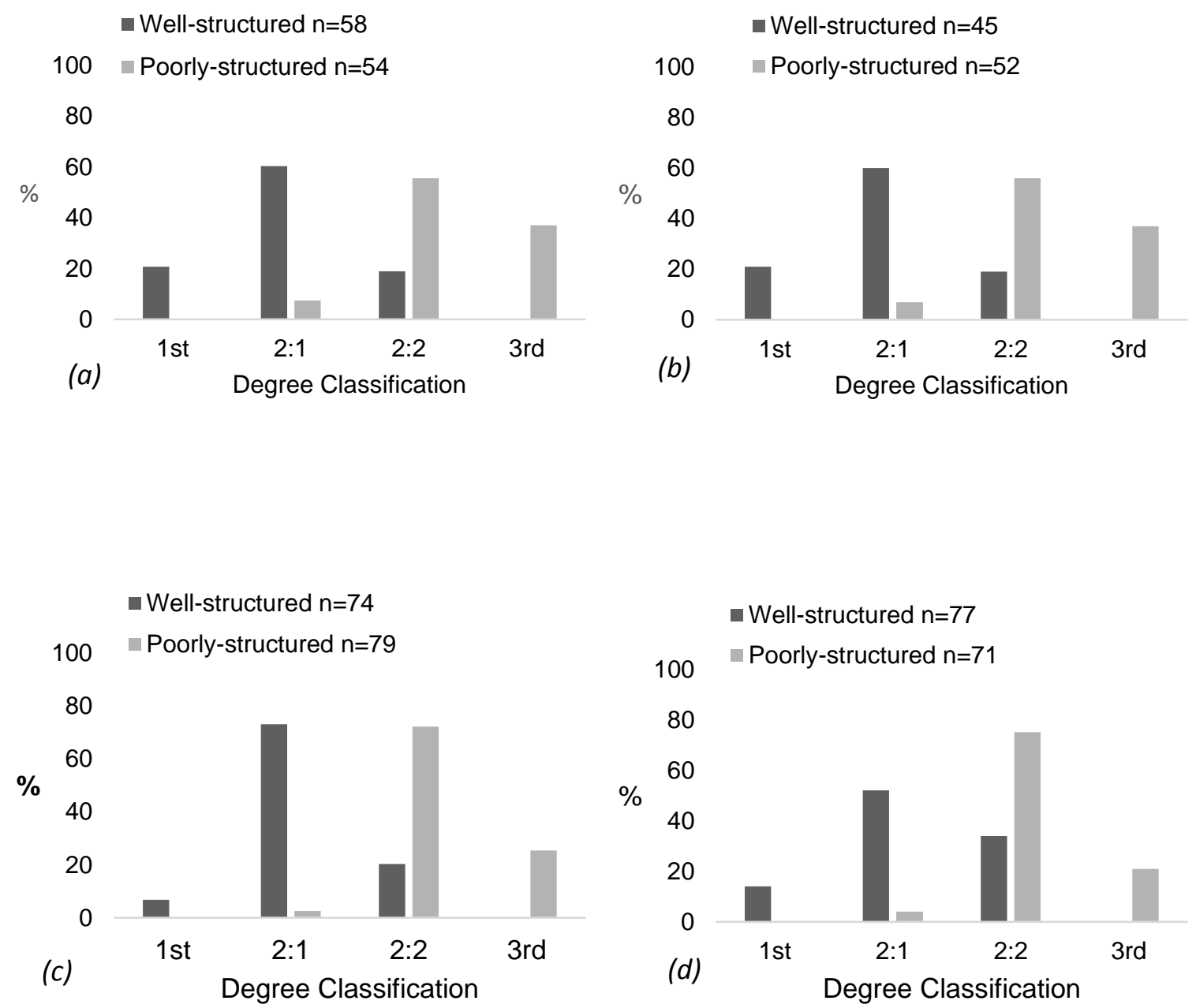

Figure 2 shows the results of the question which asked students to rate the importance of structure in an essay relative to content, both before and after the exercise. Across the 2015 and 2016 cohorts, prior to the exercise most students thought structure in an essay was as important as content before the exercise. After the exercise, there was a shift in student perceptions, with an increase in the percentage of students rating structure as more important than content. A two-tailed binomial test confirmed that the proportion of students rating structure as more important after the test $(0.48)$ was 
significantly different from the test proportion (0.09) which represented the proportion of students that rated structure as more important prior to the exercise $(p<.001)$

Figure 2: Percentage of students who reported the importance of structure relative to content (2015 and 2016 cohorts combined)

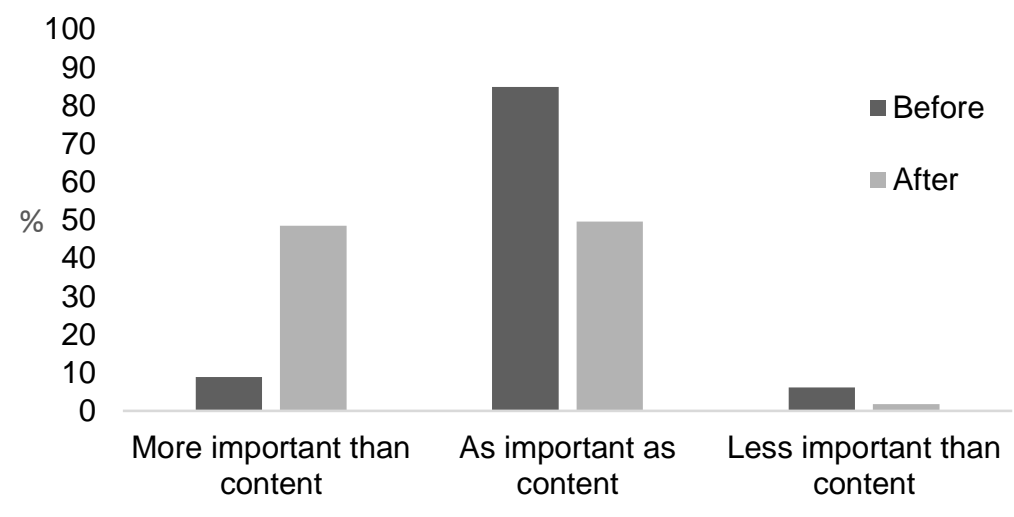

Figure 3 shows the results of the question which asked students to report the extent to which the session had raised their awareness of the importance of structuring an essay. Across the two cohorts $90.88 \%$ of students agreed that the session had increased their awareness of essay structure either a little or a lot, with around two thirds of the 2016 cohort reporting the session had helped a lot.

Figure 3: Percentage of students who reported the extent to which the session had raised their awareness of the importance of structure in an essay

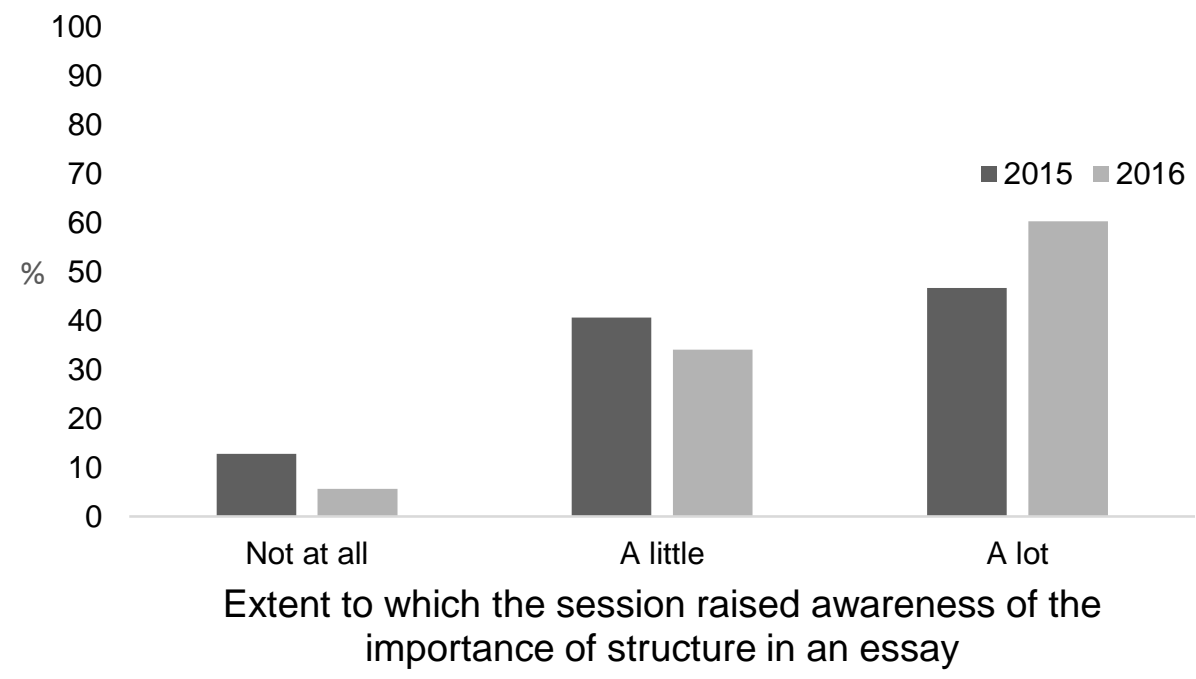




\section{Discussion}

Previous research shows that learning in $\mathrm{HE}$ is more satisfying when students are given more responsibility for their learning. Nicol (2010) argues that the best way to achieve this is to actively engage students in the assessment process, that is, by giving them opportunities to make assessment judgments about their own and others' work. Based on this position, the present study aimed to educate students on the value of structuring essays, by asking them to mark essays that were poorly or well-structured and by demonstrating how their assigned marks differed in each case.

In keeping with the hypotheses, it was shown that students consistently assigned higher grades to a well-structured essay than a poorly structured essay that contained more content. In addition, the results also showed an increase in the number of students who recognised the importance of structure in essay writing after the exercise. This element in particular, falls in line with the 'self-regulation model' of learning (Nicol, 2010) and supports the hypothesis that allowing students to engage in this activity results in changes in perceptions (i.e. internal outcomes; Nicol \& McFarlane-Dick, 2006). Through the information provided, students were also encouraged to translate this to external outcomes (i.e. essay writing in their exams).

The main aim of this exercise was to highlight to students that having a well-structured essay is superior to a poorly-structured essay which clearly impacts on the marks it achieves. The exercise was supported by traditional lecture slides on how to structure essays and paragraphs, and we hoped that by shifting internal outcomes, students would become more receptive to the importance of using the information provided on how to structure an essay. Although the results in the present study show that the exercise raised awareness of the importance of structure for most students, we did not measure whether this had an impact on the receptiveness of students to the information on essay writing. That is, once students are aware of the importance of structure in an essay are they more open to receiving guidance on how to structure an essay effectively? Research from Archer (2008) seems to suggest this would be the case as students were open to learning how to structure essays more effectively once the Writing Centre had highlighted it as an issue. However, this was a qualitative study with only 40 students based in a South African University. Future research could therefore use a more diverse, large set of students and use quantitative methods to look at relationships between changes in student awareness and the degree to which students are willing to engage with information on writing good essays. At the end of the session outlined in the present study, students were encouraged to collect a copy of the essay they did not mark. This allowed students to be able to make direct comparisons between the well-structured and the poorly-structured essay in their own time. It was hoped that having concrete examples of good and poor structure to directly compare would allow students to be able to develop good structuring skills when writing their own essays. Although we showed that the exercise in the present study was effective at changing student awareness of the importance of structure, we have no data on how these changes translated to student essay-writing practices. Future studies should therefore 
also assess whether changes in perceptions of the importance of structure do indeed have an impact on the external outcome of students writing better essays.

Although all students had access to both the well- and poorly structured essay at the end of the session, it is possible that some students may benefit from more guidance on how to structure an essay well (McCune, 2004). According to the self-regulation model, students who need more support in making use of advice in their own work (e.g. essays), experience internal outcomes but find it difficult to translate these to the external outcomes. This may particularly be the case for students from non-Western cultures who may be unfamiliar with basic essay structures (Coffin et al., 2005). The way students translate internal outcomes to external outcomes with relation to the current exercise could be affected by how they think about 'structure'. Some students conceptualise structure at a deep level where they understand the importance of the integrated structure of the essay as a whole (Campbell, Smith \& Brooker, 1998) and of linking themes to form a logical overall structure (McCune, 2004). Students at a slightly lower level often conceptualise structure as solely ordering information (Hounsell, 1997) or building information (Campbell et al, 1998) and do not acknowledge the importance of overall structure and linking themes. At an even more basic level, other students understand that essays need structure but they fail to understand how this might be done (McCune, 2004). This lack of understanding on how to successfully structure an essay poses challenges for academic staff. A useful development to the exercise described could be to extend the session to guide students through each essay. Staff could highlight the ways in which the better essay structures the content, looking at examples of scaffolding and signposting. The aim would be for more students to have a deeper understanding of structure, that an essay with good structure will involve elements such as linking themes together and having a logical overall flow to the essay, and an understanding that structure is the tool which builds relationships between the different ideas set out in the essay (Creme \& Lea, 2008).

The fact that some students have difficulties in translating their internal outcomes to external outcomes may also be due to a lack of self-regulation strategies. That is, lacking the strategies that enable them to monitor their own abilities, thoughts and motivations and to successfully translate changes in these to the completion of academic assessments or tasks (Pintrich, 2004). It might therefore be useful to offer training in self-regulation strategies early on in a degree programme. Indeed, there is evidence to suggest that training in skills such as self-reflection, keeping learning journals and taking part in self-evaluation activities increases the ability to self-regulate which then has an effect on academic attainment (Cazan, 2013).

Based on the results of the current study, active-engagement and self-regulation could be usefully expanded upon to teach essay writing on a larger scale. For instance, such seminars could be implemented within the first year of a course to provide students with the opportunity to develop their essay writing skills to a greater extent. Indeed, anecdotal feedback from the current sample of students suggested that they would have preferred to receive this information earlier on in their course. This suggestion is particularly 
noteworthy in light of the findings of Campbell et al (1998) who found that the students who conceptualised 'structure' in its most basic form (e.g. building information) had not only written the weaker essays but were more numerous among the first year students. The seminar evaluated in the current study may therefore have a greater impact on student essay-writing if it were delivered earlier on in the degree programme, giving students a longer period to practise essay writing skills.

\section{Conclusion}

In conclusion, it has been shown that good essay structure is a key element of essays which receive higher marks and this interactive exercise is an effective tool for demonstrating to students that structure effects their own value judgements of written work. This study has shown that this exercise changes students' understanding of the importance of essay structure; the next step is to evaluate whether changes in internal values are translated into changes in external outcomes (improved structure in essays). We hope the interactive exercise materials provided will be widely used by educators to engage students in the importance of essay structure. 


\section{Appendices}

\section{Appendix I}

Well-structured essay

\section{To what extent can human phobias be explained by classical conditioning?}

Plan:

Define phobia

Define CC - Pavlov 27

Phobias - Watson \& Raynor 20 - Albert

Seligman 71 - prep

(Merckelsachi et al 99 - cog biases/ soc learn)

Treatment - Wolfe Syst desen

Flooding

Gunther et al 97 multiple contexts

Classical conditioning (CC) is thought to be the main process by which most human phobias are acquired. Phobias are persistent, irrational fears of objects or situations the individual is compelled to avoid. CC is a mechanism which allows us to learn about the relationships between stimuli in the environment. It allows us to learn which stimuli predict important events and which are unimportant and can be ignored. In phobia development, this process allows us to learn maladaptive associations between events. This essay will first define CC in more detail, before showing how it can lead to phobia acquisition. The treatment of phobias that are based on the principles of $\mathrm{CC}$ will then be explored. Finally other cognitive mechanisms such as attention biases and social learning that are also important in the formation and maintenance of phobias will be outlined.

Classical conditioning allows an organism to learn an association between two stimuli and is thought to be crucial in phobia acquisition. Pavlov (1927) discovered this phenomenon in his classic experiments with dogs. He found some stimuli (e.g. food) produced an autonomic response in dogs (e.g. salivation). In this case the food was the unconditional stimulus (UCS) and the salivation was the unconditioned response (UCR). Pavlov then found that if a neutral stimulus (e.g. bell) was repeatedly paired with 
food then the bell alone produced the UCR in the dog (salivation). In this case, the bell was the Conditioned Stimulus (CS) and the salivation response was the conditioned response (CR). The CS had become significant to the dog because it predicted the arrival of food. In this experiment, the CR is identical to the UCR but this does not have to be the case. Further research has shown CC only occurs under certain conditions. Most significantly, repeated pairings of CS-UCS are usually necessary, the CS and the UCS must occur close together in time, the CS must occur before the UCS and the UCS needs to be salient. If the CS-UCS pairings stop, the CS will stop eliciting the CR and will return to being a neutral stimulus, through a process called extinction.

Watson and Raynor (1920) demonstrated directly how CC could lead to the development of phobias. They conducted a classic experiment with a boy called Albert and, through the process shown in figure 1, conditioned him to fear rats.

Figure 1 Diagram showing how CC leads to Albert's rat phobia.

Before conditioning: $\quad$ Rat $(\mathrm{CS})$ - no response

Loud bang (UCS) - startle (UCR)

During conditioning: $\quad$ Loud bang (UCS) + Rat (CS) - startle (UCR)

After conditioning: Rat (CS) - startle (CR)

They also illustrated the process of generalisation, where stimuli with physical similarity to the CS also came to elicit the CR, by showing a rabbit also made Albert startle after he acquired his rat phobia. This is an important element of CC that explains why human phobias can be triggered by an increasingly large set of stimuli and the phobia becomes increasingly debilitating.

One of the strongest lines of evidence that CC accounts for most phobias is that principles of CC can be applied to successfully treat the disorder. Phobias can be effectively treated by exposure therapy which relies on the principle of extinction. Exposure therapy takes two main forms: (1) flooding where a patient is acutely exposed to the CS until the CR stops; (2) systematic desensitisation, as proposed by Wolfe. In this treatment, the patient is taught to physically relax, then they create a hierarchy of fearful situations. They then work through the fearful situations starting with the least fearful and counteract it with relaxation. They then work through the situations until none of them elicit the CR. In order to maintain the extinction obtained in therapy and to prevent relapses, a study with rats has indicated exposure treatment should take place in multiple contexts rather than just one (Gunther et al, 1997).

Although the principles of $\mathrm{CC}$ can lead to both the acquisition and treatment of phobias, it does not explain the phenomenon entirely. Phobias can be obtained vicariously, through social learning and can be maintained by cognitive processes such as attentional biases (Merckelback et al 1999). Operant conditioning is also important in the maintenance of avoidance responses which are key to maintaining phobias. 
In conclusion, CC provides a good model for how specific phobias can be acquired and treated, however, it does not provide an entire explanation. Other factors such as operant conditioning, cognitive biases and social learning are also key in the maintenance and acquisition of human phobias. 


\section{Appendix ii \\ Poorly structured essay}

\section{To what extent can human phobias be explained by classical conditioning?}

Pavlov (1927) discovered classical conditioning (CC) quite by chance when doing experiments on dog digestion. He found that unconditional stimuli (UCS) produced unconditional response (UCR). If the UCS was then paired with a previously neutral stimulus several times, the neutral stimulus would then become the conditional stimulus (CS) and in the end produce a conditioned response (CR) which usually resembles the UCR. In Pavlov's experiments, the food was the UCS, salivation was the UCR . A bell was the CS and the salivations following just the presentation of the bell was the CR. The CS has become significant to the dog because it predicts food (UCS). CC is a mechanism which allows us to learn about relationships between stimuli in the environment. It allows us to learn which stimuli predict important events and which are unimportant stimuli and should be ignored.

Repeated pairings of CS-UCS are usually necessary in order to get successful conditioning. Also the CS and UCS have to occur close together in time, the CS must occur before the UCS and the UCS needs to be a salient stimulus. If the UCS-CS pairings stop happening, the $C S$ will stop eliciting the $C R$ and will return to being neutral stimulus, through a process called extinction. Generalisation is a process by which other neutral stimuli which physically bear some resemblance to the CS also become CSs without needing to be paired with the UCS and trigger the CR.

Little Albert developed a rat phobia through the pairing of a rat and the presentation of a loud bang. Watson and Raynor (1920) ensured at the start of the experiment that Albert was not afraid of rats and they were therefore neutral stimulus. They also knew he was afraid of loud bangs. Loud bangs caused Albert to produce an UCR of startling and crying. They repeatedly paired the UCS to loud bangs with the presentation of the rat (CS). At the end, when they presented Albert with a rat (CS), he produced the CR of startling and crying, which was very similar to his UCR to the loud bangs. Little Albert generalised this learnt fear to many other objects including a rabbit. This is because of generalisation, which leads to stimuli with some physical similarity to rats (CS) such as rabbits, also eliciting the $\mathrm{CR}$.

Phobias can be obtained vicariously through social learning and can be maintained by cognitive processes such as attentional biases (Merckelback et al, 1999). Operant conditioning is also important in the maintenance of avoidance responses which are key to maintaining the phobia. Treatment of phobias may be more successful if treatment is carried out in multiple locations. In order to maintain the extinction obtained in therapy and prevent relapse a study with rats has indicated that the exposure treatment should occur in multiple context rather than just one (Gunther et al, 1997).

Phobias are persistent irrational fears of an object or situation that an individual feels compelled to avoid. Phobias can be effectively treated by exposure therapy where the patient is exposed to the feared CS during treatment to cause extinction. This can take 
two main forms: (1) flooding where a patient is exposed to the CS acutely until the CR stops (2) Systematic desensitisation as proposed by Wolfe. In this treatment, the patient is taught to physically relax, then they create a hierarchy of fearful situation. They then work through the fearful situations starting with the least fearful and counteract it with relaxation until that situation no longer elicits the $\mathrm{CR}$.

Seligman (1971) introduced the notion of 'preparedness'. He proposed that CC works most effectively with CS stimuli that is biologically relevant and naturally important to the survival of the species. He did an experiment that showed humans need significantly more pairings of a shock and a picture of a flower for the flower picture alone to elicit the $\mathrm{CR}$, than photos of spiders or snakes. Indeed, most human phobias are of potential predators. 


\section{References}

Andrews, R. (2010). The End of the Essay? Teaching in Higher Education, 8(1), 117-128. https://doi.org/10.1080/1356251032000052366

Archer, A. (2008). Investigating the effect of Writing Centre interventions on student writing. South African Journal of Higher Education, 22(2), 248-264. https://doi.org/10.4314/sajhe.v22i2.25784

Bennett, K., \& Stevens, S. (2015). Inclusivity in the scientific curricula: barriers to participation in workshops and peer review to improve essay writing. PedRIO Paper, 7.

Bjork, L., Brauer, G., Rienecker, L., \& Stray Jorgensen, P. (2006). Teaching Academic Writing in European Higher Education (Studies in Writing). Kluwer Academic Publishers.

Campbell, J., Smith, D. \& Brooker, R. (1998). From conception to performance: How undergraduate students conceptualise and construct essays. Higher Education 36, 449-469. https://doi.org/10.1023/A:1003451627898

Cazan, A. (2013) Teaching self-regulated learning strategies for Psychology students. Procedia - Social and Behavioural Sciences, 78, 74-747. https://doi.org/10.1016/j.sbspro.2013.04.387

Chur-Hansen, A. (2000). Medical students' essay-writing skills: criteria-based self-and tutor-evaluation and the role of language background. Medical Education, 34(3), 194-198. https://doi.org/10.1046/j.1365-2923.2000.00457.x

Coffin, C., Curry, M. J., Goodman, S., Hewings, A., Lillis, T., \& Swann, J. (2005). Teaching Academic Writing: A Toolkit for Higher Education. Routledge.

Creme, P., \& Lea, M. (2008). Writing At University: A Guide For Students. McGraw-Hill Education (UK).

Daud, N. S. M., Daud, N. M., \& Kassim, N. L. A. (2016). Second Language Writing Anxiety: Cause Or Effect? Malaysian Journal of ELT Research, 1(1), 19.

Dearing Report (1997). Higher Education in the learning society Main Report. London: Her Majesty's Stationery Office.

Dochy, F. J. R. C., Segers, M., \& Sluijsmans, D. (1999). The use of self-, peer and co-assessment in higher education: A review. Studies in Higher Education, 24(3), 331-350. https://doi.org/10.1080/03075079912331379935

ESRC (2014) Improving literacy with grammar methods. Retrieved $8^{\text {th }}$ February 2017 from http://www.esrc.ac.uk/news-events-and-publications/impact-case-studies/improving-literacy-withgrammar-methods/).

Ganobcsik-Williams, L. (2010). Academic Writing in Higher Education: A Brief Overview. Research Intelligence [online].

Green, S. J. (2016). Teaching Disciplinary Writing as Social Practice: Moving Beyond 'text-in-context' Designs in UK Higher Education. Journal of Academic Writing, 6(1), 98-107. https://doi.org/10.18552/joaw.v6i1.286

Hilgers, T. L., Hussey, E. L., \& Stitt-Bergh, M. (1999). "As You're Writing, You Have these Epiphanies" What College Students Say about Writing and Learning in their Majors. Written Communication, 16(3), 317-353. https://doi.org/10.1177/0741088399016003003 
Hounsell, D. (1997). Contrasting Conceptions of essay-writing. In F. Marton, D Hounsell, \& N. Entwistle (Eds.). The Experience of Learning: Implications for Teaching and Studying in Higher Education (pp.106-125). Edinburgh, Scottish Academic Publishers.

Lea, M. R. \& Street, B.V. (1998) Student writing in higher education: An academic literacies approach, Studies in Higher Education, 23:2, 157-172. https://doi.org/10.1080/03075079812331380364

Lillis, T., \& Turner, J. (2001). Student Writing in Higher Education: Contemporary confusion, traditional concerns. Teaching in Higher Education, 6(1), 57-68.

https://doi.org/10.1080/13562510020029608

McCune, V. (2004). Development of first-year students' conceptions of essay writing. Higher Education, 47, 257-282. https://doi.org/10.1023/B:HIGH.0000016419.61481.f9

Mowl, G., \& Pain, R. (1995). Using self and peer assessment to improve students' essay writing: A case

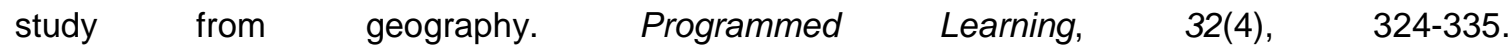
https://doi.org/10.1080/1355800950320404

Nicol, D (2010) The foundation for graduate attributes: developing self-regulation through self and peer assessment. Published by The Quality Assurance Agency for Higher Education.

Nicol, D.J. \& Macfarlane-Dick, D. (2006). Formative assessment and self-regulated learning: A model and seven principles of good feedback practice. Studies in Higher Education, 31(2), 199-218. https://doi.org/10.1080/03075070600572090

Pintrich, P.R. (2004) A conceptual framework for assessing motivation and self-regulated learning in college students. Educational Psychology Review, 16(4), 385-407. https://doi.org/10.1007/s10648004-0006-x

Prosser, M. \& Webb, C. (1994). Relating the process of undergraduate essay writing to the finished $\begin{array}{lllll}\text { product. Studies in Higher Education, 19(2), } & \text { 125-138. }\end{array}$ https://doi.org/10.1080/03075079412331381987 